\title{
Determinants of Domestic Violence in Women of Reproductive Age in Rwanda
}

\author{
FaustinHabyarimana ${ }^{1,3 *}$, TemesgenZewotir ${ }^{2}$, Shaun Ramroop ${ }^{1}$ \\ ${ }^{1}$ University of KwaZulu-Natal, Pietermaritzburg Campus, South Africa \\ ${ }^{2}$ University of KwaZulu-Natal, Westville Campus, Durban, South Africa \\ ${ }^{3}$ University of Rwanda, College of Education, Kigali, Rwanda \\ *singizwabb@gmail.com,ramroops@ukzn.ac.za, zewotir@ukzn.ac.za
}

\begin{abstract}
Domestic violence is a global public health problem. It is prevalent in both the developed world and developing countries. The objective of this study is to identify the factors that are associated with domestic violence against women of reproductive age in Rwanda. The data from the 2014/2015 Rwanda demographic and health survey were used. Generalized linear mixed model was used to account for random effects, overdispersion of residual and heterogeneity. The findings of this study revealed that wealth quintiles, education level of the husband or partner, polygamy, alcohol status of husband or partner, size of the family, number of sexual partners including the husband in the last 12 months, the province the victim lived in, the ownership of an asset in the form of a house or land and the societal attitude towards wife-beating, were the determinants of domestic violence in women of reproductive age. The findings of the risk factors in the current study can help the policy makers, public health workers and institutions in charge of gender monitoring in Rwanda to come up with effective strategies to reduce the domestic violence levels directed against women.
\end{abstract}

Keywords: Domestic violence, GLMM, Rwanda, RDHS, women

\section{Introduction}

Domestic violence was defined as "any act of gender-based violence that results in, or is likely to result in, physical, sexual or psychological harm or suffering that is used towards adult or adolescent women by former or current intimate partners, including threats of such acts, coercion or arbitrary deprivations of liberty, whether occurring in public or private life"(World Health Organization, 1997).Domestic violence is a worldwide public health concern. It is prevalent in both the developed world and in those regions that are still developing. It has been found to be perpetrated by both men and women but generally women are more likely to be victims of that violence. The levels of domestic violence among women of reproductive age that become victims varies within communities and between countries and from region to region, because of certain factors associated with the cultural beliefs, socioeconomic conditions, differing religions and traditions of the various areas (World Health Organization, 1997). The lifetime risk of becoming a victim of domestic violence for women, specifically physical violence and sexual violence, in the East African community ranges from $14.1 \%$ in Kenya to $28 \%$ in Uganda and $40 \%$ in Tanzania to $56 \%$ in Uganda respectively (Ministry of Health (Tanzania) et al., 2016; KNBS, 2010; UBOS, 2012). There are many negative health consequences that result from domestic violence in women, children and the family in general. Some of these consequences may undermine the psychological or emotional well-being of the victim, and might sometimes even result in serious consequences for victims such as mental and physical health illnesses, including poor reproductive and sexual health (Amoakohene, 2004; Beydoun et al., 2012; Johnston \& Naved, 2008; Kumar et al., 2005; Sinha et al., 2012). Acts of physical violence that are directed at women whilst in pregnancy are highly related to both maternal and neonatal mortality and morbidity (Pool et al., 2014).

Several studies in literature suggest a number of main factors associated with domestic violence. Sociological factors include aspects such as low levels of education, economic vulnerability, stress and a closed social network, social norms that are supportive of violence and community factors, such as feeble community sanctions against domestic violence and traditional gender stereotypes that sanction violence against women (Bhatta, 2014; Koenig et al., 2006; Krug et al., 2002) among others. The relationship factors include marital instability, economic stress and poor family functioning, while the family factors include communication problems, male dominance, and poor relationship and conflict resolution skills of the couples where domestic violence is known to occur (Khader et al., 2013; Adjah \&Agbemafle, 2016; Courtenay, 2000). The government of Rwanda has legislated many initiatives to help prevent and eradicate gender-based violence. A few of these initiatives are listed at national police stations, in the offices of prosecuting authorities, in the Ministry of Defence and in gender monitoring and evaluation, among others (Holmes, 2014). The government has also 
made many reforms and laws condemning all forms of domestic violence; included in this is the issue of marital rape and gender inequalities that are discriminatory towards women, amongst others (Official Gazette of the Republic of Rwanda, 2009). In order to complement the government's efforts to respond to genderbased violence, in 2009 the Isange One-Stop Centre was founded (Holmes, 2014; Immigration and Refugee Board of Canada, 2013; Ward, 2013). This centre provides free services for the survivors of child domestic abuse and gender-based violence and is available to victims countrywide. The lifetime prevalence of physical or sexual violence against women of reproductive age in Rwanda continues to be high, but of recent times a decreasing trend has been seen to be emerging; for instance in 2005 the rate was $33.6 \%$ of women but in 2010 it soared to $56.4 \%$ but then it dipped down in 2014/15 and was 34.4\% (National Institute of Statistics of Rwanda et al., 2015). As can be seen, this prevalence soared and almost doubled between 2005 and 2010. This may have been due to many reforms and transformations done at this period, especially in landownership and gender inequality, among others (Holmes, 2014; Official Gazette of the Republic of Rwanda, 2009).

Many authors have assessed the determinants of physical and sexual violence, for instance (Adjah \& Agbemafle, 2016)but the novelty innovation in this research is the inclusion of the psychological forms of abuse such as emotional violence. In addition, most of them used logistic regression models (Adjah \&Agbemafle, 2016; Audi et al., 2008) among others to analyse the data. These models are very useful when their assumptions are not violated (for instance, assumption of independence of observation among others). Consequently, when the data comes from a complex survey design, the measurements from the same cluster may be correlated and then the assumption of independence is violated. Therefore, the current study addressed the issue via a generalized linear mixed model (GLMM) that accounts for random effects, correlation, over-dispersion and heterogeneity. In addition, previous studies on domestic violence in Rwanda have been restricted to physical and sexual domestic violence (Thomson et al., 2015) or to provincial level (Ntaganira et al., 2008). Therefore, the current study considers physical, sexual and emotional violence nationwide. To the best of our knowledge, there was no study in literature considering physical, sexual and emotional violence and using GLMM to identify the factors associated with domestic violence against women of reproductive age in Rwanda. It is hoped that the findings from this study will help the policy makers and other public health related institutions to properly understand the determinants of domestic violence among women of reproductive age in Rwanda.

\section{Methodology}

Data source: The current study used the datafrom the 2014/2015 Rwanda Demographic and Health survey (RDHS). The survey was conducted from $9^{\text {th }}$ November 2014 to $8^{\text {th }}$ April 2015, where 12792 households were selected for the survey. The survey used the sampling frame from the 2012 population and housing census and the sampling was done in two stages. In the first stage, 492 villages known as clusters or enumeration areas were considered with probability proportional to the number of households residing in the village. In the second stage, systematic random sampling was used among the selected villages and 26 households were selected in each village. The survey included a module on domestic violence for both men and women aged between 15-59 and 15-49 years of age respectively. The survey used questionnaires to be answered by the men and women of each household. The RDHS 2014/2015 provided women dataset among others and this was used in this study. More details on sampling techniques used in the survey and data collection can be found in National Institute of Statistics of Rwanda et al. (2015).

Outcome measure: The dependent variable was whether or not the respondent experienced domestic violence. Domestic violence was defined as physical violence, sexual abuse and/or emotional and psychological violence. Physical violence was measured from the response to the question as to whether the respondent had experienced at least one of the subtypes of physical violence such as shaking, pushing, having something thrown at them, slapping, twisting one's arm, pulling one's hair, being beaten up, being hit with an object, burning on purpose, shocking, stabbing, dragging, knife threat, gun threat or threat with any other weapon. Any positive answer to the aforementioned was considered as the respondent having experienced physical violence. Similarly, sexual violence was measured from the response to the questions as to whether the respondent had experienced at least one of the subtypes of sexual violence such as the respondent being 
forced against her will to have sexual intercourse with a husband or partner and being forced to perform any sexual acts that the wife or partner did not consent to. A positive answer to any of these questions was characterised as a positive answer to being a victim of sexual violence. Finally, emotional or psychological violence was measured from the response to the questions related to all the different types of emotional violence, for example, saying something that serves to humiliate the wife or partner in front of others, threatening to hurt or harm someone close to the wife or partner, insulting or making the wife or partner feel bad about themselves. A positive answer to any of the above questions was considered as the respondent having experiencing emotional violence or psychological violence. In conclusion, any woman who responded positively to at least one of the aforementioned forms of abuse was recorded as that woman having been a victim of domestic violence.

Independent variables: The explanatory variables used in the current study were also used in various studies modelling domestic violence against women (Adjah \& Agbemafle, 2016; Beydoun et al., 2012; Bhatta, 2014; Koenig et al., 2004; Kumar et al., 2005; Pool et al., 2014; Sahn and Stifel, 2003) among others. It looked at whether the incidence of violence was related to the wife or her partner, or husband or his partner, and whether the community and family were involved. The socio-demographic characteristics of the women were recorded as to age group in years, education level attained, working status, number of sexual partners including husband in the last 12 months, ownership of an asset such as a house and/or land, the woman's earnings as compared with that of her husband or partner, the woman's perception of wife beating attitude was measured by combining all the different questions from RDHS of 2014/15. Each was recorded as a "0" for a negative answer and a " 1 " for a positive answer. If the beating was justified by the wife and she said she did things like going out without telling her husband, or if she argued with her husband, or neglected the children, or refused to have sex with husband, or she burnt the food. Any positive answer to any of these questions was considered to be an accepting of the wife-beating attitudes and not otherwise. The socioeconomic and demographic characteristics of the husband or partners was also viewed, such as their education level, their working status, drinking status, whether there is polygamy, and the husband or partner's earnings. The community and family characteristics that were looked at were: the size of the family, wealth quintile, place of residence, region or province, person who usually decides on visits to family or relatives, on the large household expenses for the household, on the wife's health care, and on what to do with the money the husband earns.

Statistical methods: The survey was done based on multi-stage sampling, stratified sampling, cluster sampling with unequal probability of selection for elements known as complex survey design. In these surveys the cluster incorporated in the sample represents only a random sample from the populations of the clusters. When modelling the data collected from these surveys, the sampling design must be taken into consideration. The RDHS data as described in the source of data is also among complex surveys. Therefore, modelling these data based on generalized linear models may not be valid because measurements from the same cluster are correlated and therefore the assumption of independence for generalized linear model (GLM) is violated. But there are many other models in literature that can deal with this problem; for instance survey logistic regression (Habyarimana et al., 2014; Heeringa et al., 2010) and the GLMM (Ayele et al., 2012; Heeringa et al., 2010) among others. GLMM extends classical generalized lineal models by including random effects or correlation in the linear predictor. This model has many advantages over the classical generalized linear model. GLMM also allows the researcher to account for over-dispersion, heterogeneity between clusters and also to examine various sources of variation. The current study used a GLMM framework and this model is well documented in literature, for instance model building and inferences (Breslow \& Clayton, 1993; Molenberghs \& Verbeke, 2005).

Model formulation: $\operatorname{Let} Y_{i j k}$ be the domestic violence status of women $\mathrm{i}$ from $\mathrm{j}^{\text {th }}$ household and $\mathrm{k}^{\text {th }}$ cluster and $Y_{i j k}=1$ if the women i responds positively to domestic violence and zero otherwise, $x_{i j k}$ be the ith row matrix for the fixed effects of independent variables; $a n d z_{i j k}$ be the $i^{\text {th }}$ row matrix of the random effects.

Therefore, the basic formulation of GLMM in matrix form is given by

$g(\mu)=\operatorname{logit}(\mu)=\mathrm{X} \beta+\mathrm{Zu}(1)$,

where $\mathrm{g}($.$) is the link function, \beta$ is a vector of fixed coefficients, $u$ is a vector of the random effects and $\mathrm{u}$ is assumed to be normal distributed, and $\mu$ is the conditional mean of $Y_{i j k}$ given by 
$\mu=E\left(Y_{i j k} \mid \mathrm{u}, \mathrm{X}\right)(2)$.

PROCGLIMMIX from SAS 9.4 was utilized in the analysis of the data. In order to avoid the confounding effect, the model was fitted to each explanatory variable, one at time. Furthermore, all significant variables at $5 \%$ were fitted in multivariate GLMM. The two-way interaction effect between explanatory variables was considered in the analysis. The model goodness-of-fit was assessed based on-2 Log likelihood and chi-square test and the statistical inference for the covariance parameters were performed based on the likelihood ratio test.

\section{Results}

The current study used the survey weights for domestic violence provided by the Rwanda Demographic and Health Survey data set in order to ascertain a national level representation. Table 1 shows the prevalence of domestic violence among ever married women of reproductive age in Rwanda by each category of indicator variable and their p-value. It is observed from Table 1 that prevalence of domestic violence was $40 \%, 39.1 \%$, $27.2 \%$ and $13.5 \%$ among women with no level of education, with primary education, with secondary education and tertiary education respectively ( $p$-value<.0001).

Table 1: The prevalence of domestic violence among ever married women of reproductive age by category of indicator variable

\begin{tabular}{|c|c|c|c|c|}
\hline \multirow[t]{2}{*}{ Indicator } & \multirow[t]{2}{*}{ Category } & \multicolumn{2}{|c|}{ Domestic violence } & \multirow{2}{*}{$\begin{array}{l}\text { P- } \\
\text { value }\end{array}$} \\
\hline & & Yes N (\%) & No N (\%) & \\
\hline \multirow[t]{4}{*}{ Wife/partner education level } & No education & $96(40.0 \%)$ & $144(60.0 \%)$ & \multirow[t]{4}{*}{$<.0001$} \\
\hline & Primary & $436(39.1 \%)$ & $678(60.9 \%)$ & \\
\hline & Secondary & $43(27.2 \%)$ & $115(72.8 \%)$ & \\
\hline & Tertiary & $5(13.5 \%)$ & $32(86.5 \%)$ & \\
\hline \multirow{2}{*}{$\begin{array}{l}\text { Wife/partner perception on wife-beating } \\
\text { attitude }\end{array}$} & Not acceptable & $318(32.6 \%)$ & $658(67.4 \%)$ & \multirow[t]{2}{*}{$<.0001$} \\
\hline & Acceptable & $262(45.7 \%)$ & $311(54.3 \%)$ & \\
\hline \multirow{3}{*}{$\begin{array}{l}\text { Number of partners including husband in } \\
\text { last } 12 \text { months }\end{array}$} & 0 & $7(36.8 \%)$ & $12(63.2 \%)$ & \multirow[t]{3}{*}{.340} \\
\hline & 1 & $568(37.3 \%)$ & $954(62.7 \%)$ & \\
\hline & 2 and more & $5(62.5 \%)$ & $3(37.5 \%)$ & \\
\hline \multirow[t]{4}{*}{ Home ownership by wife or partner } & Does not know & $119(36.4 \%)$ & $208(63.6 \%)$ & \multirow[t]{4}{*}{.334} \\
\hline & Alone only & $24(30.4 \%)$ & $55(69.6 \%)$ & \\
\hline & Jointly alone & $431(38.1 \%)$ & $701(61.9 \%)$ & \\
\hline & Both alone and jointly & $6(54.5 \%)$ & $5(45.5 \%)$ & \\
\hline \multirow[t]{4}{*}{ Landownership by wife or partner } & Does not know & $162(35.5 \%)$ & $294(64.5 \%)$ & \multirow[t]{4}{*}{.050} \\
\hline & Alone only & $30(30.6 \%)$ & $68(69.4 \%)$ & \\
\hline & Jointly alone & $381(38.7 \%)$ & $604(61.3 \%)$ & \\
\hline & Both alone and jointly & $7(70.0 \%)$ & $3(30.0)$ & \\
\hline \multirow[t]{3}{*}{ Wife/partner age group } & $15-24$ & $82(32.8 \%)$ & $168(67.2 \%)$ & \multirow[t]{3}{*}{.149} \\
\hline & $25-34$ & $274(37.1 \%)$ & $464(62.9 \%)$ & \\
\hline & $35-49$ & $224(39.9 \%)$ & $337(60.1 \%)$ & \\
\hline \multirow[t]{4}{*}{ Husband/partner's education level } & No & $111(46.1 \%)$ & $130(53.9 \%)$ & \multirow[t]{4}{*}{$<.0001$} \\
\hline & Primary & $419(37.5 \%)$ & $699(62.5 \%)$ & \\
\hline & Secondary & $45(31.5 \%)$ & $98(68.5 \%)$ & \\
\hline & Tertiary & $5(10.6 \%)$ & $42(89.4 \%)$ & \\
\hline Husband/partner & Yes & $447(45.6 \%)$ & $533(54.4 \%)$ & $<.0001$ \\
\hline Drinks alcohol & No & $133(23.4 \%)$ & $436(76.6 \%)$ & \\
\hline \multirow[t]{2}{*}{ Number of wives/partners } & 1 & $533(36.6 \%)$ & $925(63.4 \%)$ & \multirow[t]{2}{*}{.004} \\
\hline & 2 and more & $47(51.6 \%)$ & $44(48.4 \%)$ & \\
\hline \multirow[t]{2}{*}{ Wife or partner currently working } & No & $69(31.4 \%)$ & $151(68.6 \%)$ & \multirow[t]{2}{*}{.044} \\
\hline & Yes & $511(38.4 \%)$ & $818(61.6 \%)$ & \\
\hline \multirow{2}{*}{$\begin{array}{l}\text { Person who usually decides on visits to } \\
\text { family or relatives }\end{array}$} & Respondent alone & $116(50.7 \%)$ & $113(49.3 \%)$ & \multirow[t]{2}{*}{$<.0001$} \\
\hline & $\begin{array}{l}\text { Respondent and } \\
\text { husband or partner }\end{array}$ & $364(32.9 \%)$ & $744(67.1 \%)$ & \\
\hline
\end{tabular}




\begin{tabular}{|c|c|c|c|c|}
\hline & $\begin{array}{l}\text { Husband or partner } \\
\text { alone }\end{array}$ & $100(47.2 \%)$ & $112(52.8 \%)$ & \\
\hline \multirow{3}{*}{$\begin{array}{l}\text { Person who usually decides on large } \\
\text { household purchases }\end{array}$} & Respondent alone & $81(56.3 \%)$ & $63(43.8 \%)$ & \multirow[t]{3}{*}{$<.0001$} \\
\hline & $\begin{array}{l}\text { Respondent and } \\
\text { husband or partner }\end{array}$ & $288(29.7)$ & $682(70.3 \%)$ & \\
\hline & $\begin{array}{l}\text { Husband or partner } \\
\text { alone }\end{array}$ & $209(48.3 \%)$ & $224(51.7 \%)$ & \\
\hline \multirow{4}{*}{$\begin{array}{l}\text { Person who usually decides on what to do } \\
\text { with the money the husband earns }\end{array}$} & Respondent alone & $28(49.1 \%)$ & $29(50.9 \%)$ & \multirow[t]{4}{*}{$<.0001$} \\
\hline & $\begin{array}{l}\text { Respondent and } \\
\text { husband or partner }\end{array}$ & $350(31.2 \%)$ & & \\
\hline & Husband or partner & & & \\
\hline & alone & $202(54.7 \%)$ & $167(45.3 \%)$ & \\
\hline \multirow{3}{*}{$\begin{array}{l}\text { Person who decides on the wife/partner's } \\
\text { health care }\end{array}$} & Respondent alone & $142(47.7 \%)$ & $156(52.3 \%)$ & \multirow[t]{3}{*}{$<.0001$} \\
\hline & Jointly & $328(33.1 \%)$ & $663(66.9 \%)$ & \\
\hline & $\begin{array}{l}\text { Husband or partner } \\
\text { alone }\end{array}$ & $110(42.3 \%)$ & $150(57.7 \%)$ & \\
\hline \multirow[t]{2}{*}{ Contraceptive method use } & Yes & $336(40.5 \%)$ & $493(59.5 \%)$ & \multirow[t]{2}{*}{.007} \\
\hline & No & $244(33.9 \%)$ & $476(66.1 \%)$ & \\
\hline \multirow[t]{4}{*}{ Size the household } & $1-2$ & $16(22.9 \%)$ & $54(77.1 \%)$ & \multirow[t]{4}{*}{.009} \\
\hline & 3 & $96(32.7 \%)$ & $198(67.3 \%)$ & \\
\hline & 4 & $133(38.3 \%)$ & $214(61.7 \%)$ & \\
\hline & 5 more & $335(40.0 \%)$ & $503(60.0 \%)$ & \\
\hline \multirow[t]{2}{*}{ Place of residence } & Urban & $70(27.8 \%)$ & $182(72.2 \%)$ & \multirow[t]{2}{*}{.001} \\
\hline & Rural & $510(39.3 \%)$ & $787(60.7 \%)$ & \\
\hline \multirow[t]{5}{*}{ Provinces } & Kigali & $53(28.8 \%)$ & $131(71.2 \%)$ & \multirow[t]{5}{*}{.006} \\
\hline & South & $139(37.4 \%)$ & $233(62.6 \%)$ & \\
\hline & West & $123(35.9 \%)$ & $220(64.1 \%)$ & \\
\hline & East & $143(37.2 \%)$ & $241(62.8 \%)$ & \\
\hline & North & $122(45.9 \%)$ & $144(54.1 \%)$ & \\
\hline \multirow[t]{5}{*}{ Wealth quintile } & Poorest & $134(47.2 \%)$ & $150(52.8 \%)$ & \multirow[t]{5}{*}{$<.0001$} \\
\hline & Poorer & $124(39.5 \%)$ & $190(60.5 \%)$ & \\
\hline & Middle & $131(38.1 \%)$ & $213(61.9 \%)$ & \\
\hline & Rich & $115(38.3 \%)$ & $185(61.7 \%)$ & \\
\hline & Richest & $76(24.8 \%)$ & $231(75.2 \%)$ & \\
\hline
\end{tabular}

It was observed from the Table 1 that the widespread presence of domestic violence was $32.6 \%$ of the women who do not tolerate a wife/partner-beating attitude and $45.7 \%$ among women who do tolerate it (p-value $<.0001$ ). The prevalence of domestic violence among women whose husband or partner drank alcohol was $45.6 \%$ and $23.4 \%$ among women whose husband or partner did not drink alcohol (p-value <.0001). It was also seen from the above table that $38.45 \%$ of women who were formally working and $31.4 \%$ of women who did not work experienced domestic violence ( $p$-value $=0.044$ ).It is observed from the Table 1 that $51.6 \%$ of women whose husband or partner had more than one wife or partner and $36.6 \%$ of women whose husband or partner had only one wife or partner have experienced any type of domestic violence (pvalue $=0.004$ ).Table 1 reveals that the percentage of women who had experienced domestic violence was higher among women from rural areas than women from urban areas $(39.3 \%$ and $27.8 \%$ respectively) (pvalue $=0.001$ ). The province of residence of the respondent was also considered. It was shown in Table 1 that the percentage of women who had experienced domestic violence was highest in the Northern Province where the rate was $45.6 \%$ of the women in the study compared to the other provinces. The lowest rate was in Kigali city with a $28.8 \%$ response rate confirming that they had experienced some form of domestic violence ( $p$-value=0.006). Socio-economic factors were also considered; for instance, wealth quintile and home ownership of the wife or partner were aspects that were investigated in this study. It was seen from the results that the percentage of women who have experienced any type of domestic violence was lower among women from richest households and higher among women from poorest households ( $p$-value <.0001). 
The indicator related to decision making was also considered. This refers to the person who usually decides on how to spend, for example, the earnings of the husband or partner. This variable was categorized as respondent alone (wife or partner), respondent and husband or partner and husband or partner alone. From Table 1 the findings show that the prevalence of domestic violence was $49.1 \%, 31.2 \%$ and $54.7 \%$ respectively among women who decide how to spend the earnings of their husband or partner alone, jointly (wife and husband or partner) and the husband or partner making that decision on their own respectively (pvalue<.000). The prevalence of domestic violence was 50.7\%, 32.9\% and $47.2 \%$ among women who decided alone on visits to family or relatives, women who decide jointly with husband or partner, and among women whose husband or partner decided alone whether to visit the family or relatives respectively ( $p$-value <.0001). In multivariate analysis the model was fitted with various covariance structures in order to choose the best. In SAS, variance component (VC) was the default and was the first to be fitted, also compound symmetry (CS), autoregressive (AR1), and unstructured (UN) were fitted to the data. We examined the value of Akaike Information Criterion (AIC) for each variance structure and the VC was found to produce the smallest AIC and it was then used in the analysis. In order to avoid possible confounding effects, the two-way interaction effect between the potential variables (wife or partner perception on wife-beating attitude and wealth index, wife or partner perception on wife-beating attitude and education level) was used in the analysis but none was found to be significant and therefore it was excluded from the analysis and the final model is shown in Table 2. The fixed effects of explanatory variables used in the model are shown in Table 2 along with their p-values; this gives us an indication of their influence on the response variable.

Table 2: Type 3 tests of fixed effects

\begin{tabular}{lccl}
\hline Effect & NumDf & $\begin{array}{c}\text { F } \\
\text { value }\end{array}$ & Pr>F \\
\hline Wealth quintiles & 4 & 4.2 & 0.0022 \\
Partner/husband drinking status & 1 & 64.57 & $<.0001$ \\
Provinces & 4 & 2 & 0.0924 \\
Partner/husband's level of education & 3 & 3.88 & 0.0089 \\
Woman's perception of wife/partner- beating attitude & 1 & 13.50 & 0.0002 \\
Size of the family & 3 & 5.58 & 0.0008 \\
Number of wives & 1 & 4.55 & 0.0332 \\
Respondent owns a house alone or jointly & 3 & 3.2 & 0.0226 \\
$\quad$ Number of partners in last 12 months including & 2 & 2.12 & 0.1206 \\
\hline
\end{tabular}

NumDf=number of degree of freedom

The fit statistics is summarized in Table 3, where twice the negative of the residual log likelihood or deviance in the final pseudo-model is 7055.29. It is also observed from Table 3 that the ratio of generalized chi-square statistics and its degrees of freedom is 0.95 which is very close to 1 and this is evidence that the residual variability in the data has been suitably modelled and therefore there is no residual over-dispersion.

Table 3: Fit statistics

\begin{tabular}{ll}
\hline -2Res Log-pseudo-likelihood & 7055.29 \\
Generalized Chi-square & 1481.28 \\
Generalized Chi-square/Df & 0.95 \\
\hline
\end{tabular}

The results from multivariate GLMM for fixed effects are summarized in Table 4. Further it was noted that the wealth quintile had a significant effect on domestic violence levels. The relationship is inversely proportional. The risk of a woman experiencing domestic violence in the poorest family was two times $(\mathrm{OR}=2.3, \mathrm{p}$ value $=0.0002$ ) more than that of a woman from the richest family. The results of this study also revealed a significant association between polygamy and domestic violence. The risk factors of a woman whose husband or partner had no other wife or partner was 0.61 less likely to experience any type of domestic violence than a female whose husband or partner had more than one wife or partner $(\mathrm{OR}=0.61$, $\mathrm{p}$-value $=0.0332)$. The study 
revealed that the domestic violence levels found in women of reproductive age were inversely proportional to the husband or partner's level of education. The risk of women whose husband had no formal education, of suffering from any form of domestic violence, was five times more than that of women whose husband or partner had a tertiary education $(\mathrm{OR}=5.388$, $\mathrm{p}$-value $=0.0014)$. The risk of experiencing domestic violence for a woman whose husband or partner had primary or secondary school education level was four and three $(\mathrm{OR}=4.064, \mathrm{p}$-value $=0.0056$ and $\mathrm{OR}=3.426$, $\mathrm{p}$-value $=0.0199)$ times more than a woman whose husband or partner had tertiary education, respectively. The woman or partner's perception of wife/partner-beating attitude is shown to be significantly associated with domestic violence in women. The risk of experiencing domestic violence for a woman who does not accept the attitude of wife/partner-beating was almost 0.7 $(\mathrm{OR}=0.665$, $\mathrm{p}$-value $=0.0005)$ times less than that of a woman who accepted the attitude of wife/partnerbeating.

Table 4: Parameter estimates of factors associated to domestic violence of women of reproductive age from multivariate GLMM

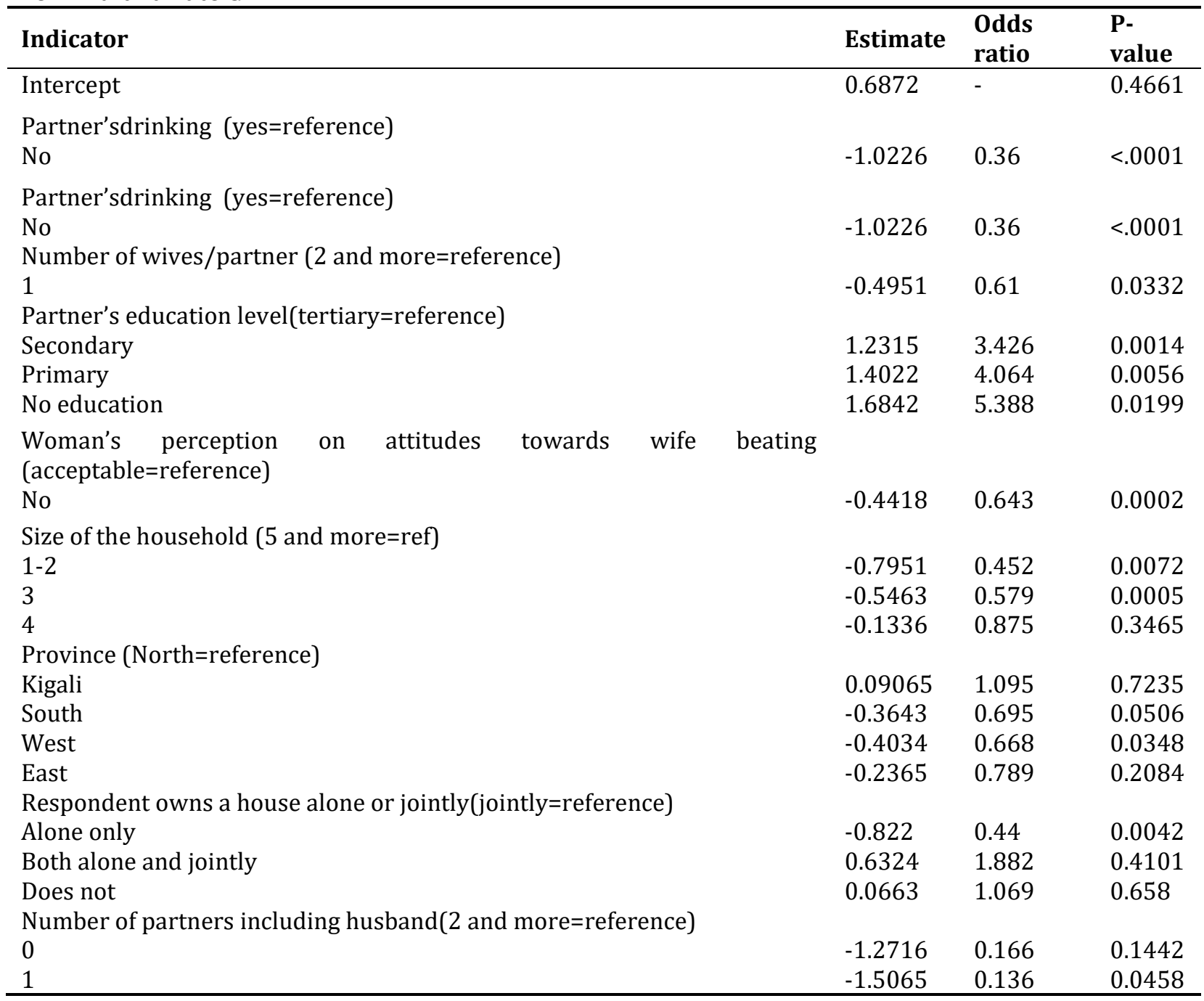

The number of household members also significantly affects any type of domestic violence levels of ever married women of reproductive age. The findings of the present study show that domestic violence increases with an increase in the size of the household. The likelihood of experiencing domestic violence by a woman whose household consisted of one to two people was $0.45(p$-value $=0.0072)$ times less than a woman whose household consisted of five or more people. A woman from a household of three people was 0.579 (OR=0.579, $\mathrm{p}$-value $=0.0005$ ) times less likely to experience domestic violence than a woman whose family consisted of 
five or more people. Alcohol status of the partner is significantly associated with domestic violence of women. A woman whose husband or partner does not drink was 0.36 (OR=0.361, p-value $<.0001)$ times less likely to experience domestic violence than a woman whose husband or partner does drink alcohol. Having multiple sex partners was also found to significantly affect the domestic violence levels suffered by women of reproductive age in Rwanda. A woman who had only one sexual partner or husband in the last 12 months was0.136(OR=0.136, $\mathrm{P}=0.045)$ times less likely to experience the domestic violence compared to a woman who had two or more sexual partners, including the husband, in the last 12 months.

The province the woman resided in was also found to significantly affect the domestic violence levels of women of reproductive age in Rwanda. The findings from the results showed that a woman residing in the Northern Province was found to experience domestic violence at a higher rate than any woman from Southern and Western provinces. For instance, a woman from the Western Province was $0.668(\mathrm{OR}=0.0 .668$, $\mathrm{p}$-value $=0.0348$ ) times less likely to experience domestic violence than a woman from the Northern Province. Nevertheless, the current study did not find a statistical significant difference between a woman from Northern and Eastern province ( $p$-value=0.2084). The ownership of a house was also found to be an important factor of domestic violence against women of reproductive age in Rwanda. The likelihood of experiencing any type of domestic violence for a woman who owned a house alone was 0.44 (OR=0.44, $\mathrm{P}=0.0042$ ) times less than that of a woman who jointly owned a house.

Discussion: The factors associated with any type of domestic violence against women of reproductive age may differ across countries, religion, culture, beliefs and traditions. The findings of this study showed that there is, in fact, a significant association between socio-economic characteristics and the levels of domestic violence that are suffered by women of reproductive age in Rwanda. Women from poorest households in the country were found to be at very high risk compared to those of the richest households. This finding concerning socio-economic factors playing some sort of important role was found elsewhere (Bamiwuye \& Odimegwu, 2014; Oduroet al., 2015; Tran et al., 2016). However, in the study carried out by Bamiwuye and Odimegwu (2014) on spousal violence in six countries from sub-Saharan Africa, it was found that domestic violence was higher among women from the rich families in Mozambique and Zambia, it was also higher from the middle classes in Nigeria and Cameroon, and it was higher from the poor families in Zimbabwe and Kenya. This disparity across the countries investigated in Africa would indicate that certain factors, unique to each country, are the driving force behind domestic violence against women in these particular countries. These factors would include cultural beliefs and policies that are associated with genders that are specific to each country or region or community.

The findings of this study showed a higher rate of prevalence of domestic violence among women whose husband or partners consumed alcohol. This finding is similar to other findings from previous studies (Ali et al., 2014; Gage, 2005; Koenig et al., 2006; Mandal \& Hindin, 2013; Semahegn \& Mengistie, 2015; Sinha et al., 2012). A number of authors, for instance Moraes and Reichenheim (2002) believe that alcohol intake causes episodes of domestic violence in a household by degrading the behaviours of the partner who is doing the drinking and creating uninhibited irrational conditions for the starting of arguments that then include insults and threats, poor judgment and impulse control, which may then result in some form of physical, sexual and/or psychological violence that is directed at the female partner. The findings of this study showed that the lower the level of the husband or partner's education, the higher the risk that his wife or partner may experience domestic violence perpetrated against them. This finding is similar to other findings(Mohamadian et al., 2016; Rada, 2014). Therefore, higher levels of education may be one of the key factors for protecting women against domestic violence. This study also examined whether the level of education of the women was associated to domestic violence and it resulted in non-significant effect. It is very difficult to measure emotional and sexual violence in women because of the cultural and traditional restraints preventing women from openly reporting abuse. However, the results of this study would indicate that as the gender inequalities that exist are reduced in ways such as poverty alleviation, and the victims become educated to know their rights better, the levels of domestic violence based against women should reduce.

The size of the household was shown to be one of the significant risk factors of domestic violence in women of reproductive age. This finding was also found by Ali et al. (2014) and Mahapatro et al. (2012). The current study considered the attitudes of both husband or partner and women, but only the women's attitudes were 
statistically significant. The findings from this study showed that women who said no to the acceptance of domestic violence against their gender were less likely to experience domestic violence. Polygamy was found to significantly affect the domestic violence levels of women of reproductive age in Rwanda. This result was also found by the National Institute of Statistics of Rwanda et al. (2015) and Ali et al. (2014). It was found that polygamy increases domestic violence mostly in the aspect of physical violence and this, in most of the cases, was accompanied by psychological or emotional violence. Polygamy may also be associated with economic violence (this violence includes the prevention of the wife or partner from making a choice about their occupation, the withholding of money for essential things such as food and medical treatment, the manipulation of family members for financial gain, and stealing from the wife or partner, among other things).The current research setting revealed a significant effect between the province which the women were from and domestic violence of women of reproductive age in Rwanda. Domestic violence levels were higher among women from the Northern Province. This finding is similar to that of the National Institute of Statistics of Rwanda et al. (2015) . This might be due to the high rates of polygamy in this particular province compared to other provinces. Homeownership by the woman alone is a pivotal factor related with lower levels of domestic violence in women of reproductive age in Rwanda. This finding was found elsewhere, for instance by Oduro et al. (2015). This shows that empowering women may offer a protective effect against domestic violence in women of childbearing age. The analysis also included land ownership but this variable was not significant in multivariate GLMM. The female ownership of properties increases a woman's economy security and reduces the willingness of that woman to tolerate violence.

Study limitations: The current study used a cross-sectional data from RDHS and this data may not be able to address causality. Therefore, longitudinal studies that will solve this problem are suggested for future work. In addition, the researchers suggest DHS to include data on economic violence.

\section{Conclusion}

The risk factors related with domestic violence in women differ both regionally and with that of other countries. In most of the cases this is a consequence of the specific cultural beliefs, traditions and policies of the particular region or country in which the woman lives. In addition to the flexible statistical modelling of the GLMM to the analysis of the RDHS data, the results of our study highlight new findings, such as the significant role of polygamy, ownership of house by wife or partner and the wife or partner's perception of the wife/partner-beating attitude. The study also revealed that other determinants of domestic violence against women of reproductive age in Rwanda were the household's wealth quintile, the size of the household, the husband or partner's education level, the province they lived in, the drinking status of husband/partner, and the number of sexual partners, including husband, the woman had in the last 12 months. The findings from this study suggest improvement on gender-based sensitization for both males and females to be better informed about the aspect of emotional or psychological violence, as well as knowing the aspects of physical, sexual and economic violence, and to continue to educate both females and males about their rights. The findings also suggest that polygamy, multiple sexual partners should continue being discouraged and policymakers and stakeholders should continue encouraging women to make their own money, in order to empower themselves economically.

Acknowledgments: The authors acknowledge National Institute of Statistics of Rwanda (NISR) [Rwanda], Ministry of Health (MOH) [Rwanda], and ICF International for the data.

\section{References}

Adjah, E. S.\& Agbemafle,I. (2016). Determinants of domestic violence against women in Ghana. BMC public health, 16(1), 368. doi. 310.1186/s12889-12016-13041-x.

Ali, A.A., Yassin, K.\& Omer, R. (2014). Domestic violence against women in Eastern Sudan. BMC public health, 14(1), 1136. doi:1110.1186/1471-2458-1114-1136.

Amoakohene, M. I. (2004). Violence against women in Ghana: a look at women's perceptions and review of policy and social responses. Social Science \& Medicine, 59(11), 2373-2385.

Audi, C. A. F., Segall-Corrêa, A. M., Santiago,S. M., Andrade, M.G. G.\&Pèrez-Escamila, R. ( 2008). Violence against pregnant women: prevlence and associated factors. Revista de Saude publica, 42(5), 877-885. 
Ayele, D. G., Zewotir, T.\&Mwambi, H.G. (2012). Prevalence and risk factors of malaria in Ethiopia. Malaria Journal, 11(1), 195.

Bamiwuye, S. O.\&Odimegwu, C. (2014). Spousal violence in sub-Saharan Africa: does household povertywealth matter? Reproductive health, 11(1), 45. doi 10.118611742-118614755-118611711118611745.

Beydoun, H. A., Beydoun, M.A., Kaufman, J. S., Lo, B. \& Zonderman, A. B.(2012). Intimate partner violence against adult women and its association with major depressive disorder, depressive symptoms and postpartum depression: a systematic review and meta-analysis. Social Science \& Medicine, 75(6), 959975.

Bhatta, D. N. (2014). Shadow of domestic violence and extramarital sex cohesive with spousal communication among males in Nepal. Reproductive health, 11(1), 44.doi.org/10.1186/1742-4755-11-44.

Breslow, N. E. \& Clayton, D. G. (1993). Approximate inference in generalized linear mixed models. Journal of the American Statistical Association, 88(421), 9-25.

Courtenay, W. H. (2000). Constructions of masculinity and their influence on men's well-being: a theory of gender and health. Social Science \& Medicine, 50(10), 1385-1401.

Gage, A. J. (2005). Women's experience of intimate partner violence in Haiti. Social Science \& Medicine, 61(2), 343-364.

Habyarimana, F., Zewotir, T. \& Ramroop, S. (2014). A proportional odds model with complex sampling design to identify key determinants of malnutrition of children under five years in Rwanda. Mediterranean Journal of Social Sciences, 5(23), 1642-1648.

Heeringa, S. G., West, B. T. \& Berglund, P. A. (2010). Applied survey data analysis: CRC Press.

Holmes, G. (2014). Gendering the Rwanda Defence Force: A Critical Assessment. Journal of Intervention and Statebuilding, 8(4), 321-333.

Immigration and Refugee Board of Canada. (2013). Rwanda: Domestic violence, including legislation, state protection, services and legal recourse available to victims (2011-September2013). available online: http://www.ecoi.net/local_link/261949/375254_en.html (accessed on 20 July 2017).

Johnston, H. B. \& Naved, R. T. (2008). Spousal violence in Bangladesh: a call for a public-health response. Journal of health, population, and nutrition, 26(3), 366-377.

Kenya National Bureau of Statistics (KNBS), \&ICF Macro. (2010).Kenya Demographic and Health Survey 2008-09, Calverton, Maryland: KNBS \& ICF Macro.

Khader, J. A., AbdElsalam, N. M., Shamsuddin, S., Rehman, S. U. \& Muneer, S. (2013). Some Reasons behind the Violence of the Women's Rights in Pakistan. Life Science Journal, 10(2), 1007-1013

Koenig, M. A., Lutalo, T., Zhao, F., Nalugoda, F., Kiwanuka, N., Wabwire-Mangen, F.\& Serwadda, D. (2004). Coercive sex in rural Uganda: prevalence and associated risk factors. Social Science \& Medicine, 58(4), 787-798.

Koenig, M. A., Stephenson, R., Ahmed, S., Jejeebhoy, S. J. \& Campbell, J. (2006). Individual and contextual determinants of domestic violence in North India. American journal of public health, 96(1), 132-138.

Krug, E. G., Mercy, J. A., Dahlberg, L. L.\& Zwi, A. B. (2002). The world report on violence and health. The lancet, 360(9339), 1083-1088.

Kumar, S., Jeyaseelan, L., Suresh, S.\& Ahuja, R. C. (2005). Domestic violence and its mental health correlates in Indian women. the British journal Of psychiatry, 187(1), 62-67.

Mahapatro, M., Gupta, R.\& Gupta, V. (2012). The risk factor of domestic violence in India. Indian journal of community medicine: official publication of Indian Association of Preventive \& Social Medicine, 37(3), 153-157.

Mandal, M.\& Hindin, M. J. (2013). Men's controlling behaviors and women's experiences of physical violence in Malawi. Maternal and child health journal, 17(7), 1332-1338.

Ministry of Health, Community Development, Gender, Elderly and Children (MoHCDGEC)[Tanzania Mainland], MoH, Ministry of Health[Zanzibar], M., National Bureau of Statistics(N.B.S), N., Office of the Chief Government Statistician(OCGS), O.\& I.C.F, I. (2016). Tanzania Demographic and Health Survey and Malaria indicator Survey(TDHS-MIS) 2015-16. Dar es Salaam, Tanzania, and Rockville, Maryland, USA: MoHCDGEC, MoH, NBS, OCGS, and ICF.

Mohamadian, F., Hashemian, A., Bagheri, M.\& Direkvand-Moghadam, A. (2016). Prevalence and risk factors of domestic violence against Iranian women: a cross-sectional study. Korean journal of family medicine, 37(4), 253-258. 
Molenberghs, G.\&Verbeke, G.(2005). Models for discrete longitudinal data: New York: Springer-Verlag, 265295.

Moraes, C. L. \& Reichenheim, M. E. (2002). Domestic violence during pregnancy in Rio de Janeiro, Brazil. International Journal of Gynecology \& Obstetrics, 79(3), 269-277.

National Institute of Statistics of Rwanda (NISR) [Rwanda], Ministry of Health(MoH) [Rwanda], and ICF International. 2015. Rwanda Demographic and Health Survey 2014-15. Rockville, MD, USA: NISR, $\mathrm{MoH}$, \& ICF International.

Ntaganira, J., Muula, A. S., Masaisa, F., Dusabeyezu, F., Siziya, S.\& Rudatsikira, E. (2008). Intimate partner violence among pregnant women in Rwanda. BMC women's health, 8(1), 17.doi.org/10.1136/bmjopen-2016-013155.

Oduro, A. D., Deere, C. D.\& Catanzarite, Z. B. (2015). Women's wealth and intimate partner violence: insights from Ecuador and Ghana. Feminist Economics, 21(2), 1-29.

Official Gazette of the Republic of Rwanda. (2009). Official Gazette of the Republic of Rwanda number 14 of 06 April 2009 page 81.Available online: http://www.migeprof.gov.rw/fileadmin/_migrated/content_uploads/GBV_Law_in_Official_Gazette_n o_14_of_06-04-2009.pdf(Accessed on 10 August 2017).

Pool, M. S., Otupiri, E., Owusu-Dabo, E., De Jonge, A.\& Agyemang, C. (2014). Physical violence during pregnancy and pregnancy outcomes in Ghana. BMC pregnancy and childbirth, 14(1), 71.doi.org/10.1186/1471-2393-14-71.

Rada, C. (2014). Violence against women by male partners and against children within the family: prevalence, associated factors, and intergenerational transmission in Romania, a cross-sectional study. BMC public health, 14(129), 1-15.

Sahn, D. E.\& Stifel, D. (2003). Exploring alternative measures of welfare in the absence of expenditure data. Review of income and wealth, 49(4), 463-489.

Semahegn, A.\& Mengistie, B. (2015). Domestic violence against women and associated factors in Ethiopia; systematic review. Reproductive health, 12(1), 78.

Sinha, A., Mallik, S., Sanyal, D., Dasgupta, S., Pal, D.\& Mukherjee, A. (2012). Domestic violence among ever married women of reproductive age group in a slum area of Kolkata. Indian journal of public health, 56(1), 31-36.

Thomson, D. R., Bah, A. B., Rubanzana, W. G.\& Mutesa, L. (2015). Correlates of intimate partner violence against women during a time of rapid social transition in Rwanda: analysis of the 2005 and 2010 demographic and health surveys. BMC women's health, 15(1), 96. doi:10.1186/s12905-12015-1025712903.

Tran, T. D., Nguyen, H.\& Fisher, J. (2016). Attitudes towards intimate partner violence against women among women and men in 39 low-and middle-income countries. PloS one, 11(11), e0167438.

UBOS.(2012). Uganda demographic and health survey 2011. Kampala and Claverton: Uganda Bureau of Statistics and ICF International Inc.

Ward, J. (2013). Violence Against Women in Conflict, Post-conflict and Emergency Settings Available online: http://www.endvawnow.org/uploads/modules/pdf/1405612658.pdf (Accessed on 20 December 2017).

World Health Organization, W. (1997). WHO/WHD Violence against women: a priority health issue Geneva: World Health Organization. Available online :http://apps.who.int/iris/bitstream/10665/63553/1/WHO_FRH_WHD_97.8.pdf (accessed on 20 December 2017). 